BULLETIN OF THE

AMERICAN MATHEMATICAL SOCIETY

Volume 80, Number 4, July 1974

\title{
ON THE EXTENSION OF BASIC SEQUENCES TO BASES
}

\author{
BY IVAN SINGER
}

Communicated by Robert Bartle, December 12, 1973

\begin{abstract}
We show that there exists a subspace $G$ with a basis of some Banach space $E$ with a basis, such that no basis of $G$ can be extended to a basis of $E$.
\end{abstract}

A sequence $\left\{x_{n}\right\}$ in a (real or complex, infinite dimensional) Banach space $E$ is called (a) a basis of $E$, if for every $x \in E$ there is a unique sequence of scalars $\left\{\alpha_{n}\right\}$ such that $x=\sum_{i=1}^{\infty} \alpha_{i} x_{i}$; (b) a basic sequence if $\left\{x_{n}\right\}$ is a basis of its closed linear span $\left[x_{n}\right]$ in $E$. The following problem was raised by A. Pełczynski (see [5] or [7, p. 27, Problem 4.1]): Let $\left\{y_{n}\right\}$ be a basic sequence in a Banach space $E$ with a basis. Does there exist a basis $\left\{x_{n}\right\}$ of $E$ with the property that for each $n$ there is an index $i_{n}$ such that $x_{i_{n}}=y_{n}$ ? Or, in other words, can $\left\{y_{n}\right\}$ be extended to a basis of $E$ ?

A. Pełczyński and H.P. Rosenthal have communicated to us that recently they have solved this problem in the negative, for $E=L^{p}([0,1])(2<p<\infty)$ and $E=L^{1}([0,1])[6]$. However, since in their counterexamples $\left\{y_{n}\right\}$ had some permutation $\left\{y_{\sigma(n)}\right\}$ which can be extended to a basis of $E$, they have raised the problem whether there exists a basic sequence $\left\{y_{n}\right\}$ in some Banach space $E$ with a basis, such that no permutation $\left\{y_{\sigma(n)}\right\}$ of $\left\{y_{n}\right\}$ can be extended to a basis of $E$. In the present note we shall show even more, namely, that there exists a subspace $G$ with a basis of some Banach space $E$ with a basis, such that no basis of $G$ can be extended to a basis of $E$. Our proof is very short, but uses deep results of Enflo [1], Lindenstrauss [4] and Johnson-Rosenthal-Zippin [3].

EXAMPLE. Let $F$ be a separable Banach space which has no basis [1]. By [4] there exists a separable Banach space $B$ such that the conjugate space $B^{*}$ has a shrinking basis and that $B^{* *} / \pi(B)$ is isomorphic to $F$, where $\pi$ is the canonical embedding of $B$ into $B^{* *}$. Then $B^{* *}$ has a basis (see e.g. [7, Theorem 4.2, p. 272]) and by [3, Theorem 1.4(a)], $B$ has a shrinking basis, so $\pi(B)$ has a shrinking basis. However, no basis $\left\{y_{n}\right\}$ of $G=\pi(B)$ can be extended to a basis $\left\{y_{n}\right\} \cup\left\{y_{n}^{\prime}\right\}$ of $E=B^{* *}$, since otherwise the quotient space $E / G=B^{* *} / \pi(B)$ would have a basis, namely $\left\{\omega\left(y_{n}^{\prime}\right)\right\}$,

AMS (MOS) subject classifications (1970). Primary 46B1.5; Secondary 46A35. 
where $\omega$ is the canonical mapping of $E$ onto $E / G$ (see e.g. [2, §2, Theorem 1], or [7, Proposition 4.1, p. 27]), whence $F$ would have a basis, in contradiction with our choice of $F$. This completes the proof.

REMARK. W. B. Johnson has observed that if we start with a separable Banach space $F$ which does not have the bounded approximation property (i.e. there is no sequence of finite rank operators $\left\{v_{n}\right\}$ on $F$ such that $\lim _{n \rightarrow \infty} v_{n}(z)=z$ for all $\left.z \in F\right)$, then our proof above also yields an example of a subspace $G=\pi(B)$ with a basis of the Banach space $E=B^{* *}$ with a basis, such that there exists no sequence of finite rank operators $\left\{u_{n}\right\}$ on $E$ satisfying $\lim _{n \rightarrow \infty} u_{n}(x)=x$ for all $x \in E$ and $u_{n}(G) \subset G$ for $n=1,2, \cdots$.

Finally, let us also raise two problems suggested by the preceding: (1) In which Banach spaces $E$ with a basis does there exist (a) a basic sequence $\left\{y_{n}\right\}$ which cannot be extended to a basis of $E$ ? (b) a basic sequence $\left\{y_{n}\right\}$ such that no permutation $\left\{y_{\sigma(n)}\right\}$ of $\left\{y_{n}\right\}$ can be extended to a basis of $E$ ? (c) a subspace $G$ with a basis such that no basis of $G$ can be extended to a basis of $E$ ? It is even conceivable that every Banach space $E$ with a basis, which is not isomorphic to $l^{2}$, contains such a basic sequence $\left\{y_{n}\right\}$ or such a subspace $G$. (2) If $u$ is a continuous linear mapping of $l^{1}$ onto a separable Banach space $F$, does $\operatorname{Ker} u$ have a basis? (The answer is not known even for $F=l^{2}$ or $c_{0}$.) An affirmative answer would yield another example of the above type, since there exists a continuous linear mapping $u$ of $l^{1}$ onto any separable Banach space $F$ which has no basis and then $E / \operatorname{Ker} u$ is isomorphic to $F$, so one could take $G=\operatorname{Ker} u$.

\section{REFERENCES}

1. P. Enflo, A counterexample to the approximation problem in Banach spaces, Acta Math. 130 (1973), 309-317.

2. B. R. Gelbaum, Notes on Banach spaces and bases, An. Acad. Brasil. Ci. 30 (1958), 29-36. MR 20 \#5419.

3. W. B. Johnson, H. P. Rosenthal and M. Zippin, On bases, finite dimensional decompositions and weaker structures in Banach spaces, Israel J. Math. 9 (1971), 488506. MR 43 \#6702.

4. J. Lindenstrauss, On James's paper "Separable conjugate spaces", Israel J. Math. 9 (1971), 279-284. MR 43 \#5289.

5. A. Pełczyński, Some open questions in functional analysis, A lecture given to Louisiana State University, 1966 (dittoed notes).

6. A. Pełczyński and H. P. Rosenthal (in preparation).

7. I. Singer, Bases in Banach spaces. I, Die Grundlehren der math. Wissenschaften, Band 154, Springer-Verlag, New York, 1970. MR 45 \#7451.

Department of Mathematics, University of Amsterdam, Amsterdam, Holland Institute of Mathematics, Academy of the Socialist Republic of Romania, BUCHAREST, ROMANIA 